\title{
ITRF2008: an improved solution of the international terrestrial reference frame
}

\author{
Zuheir Altamimi · Xavier Collilieux • \\ Laurent Métivier
}

Received: 17 September 2010 / Accepted: 10 January 2011 / Published online: 3 February 2011

(C) The Author(s) 2011. This article is published with open access at Springerlink.com

\begin{abstract}
ITRF2008 is a refined version of the International Terrestrial Reference Frame based on reprocessed solutions of the four space geodetic techniques: VLBI, SLR, GPS and DORIS, spanning 29, 26, 12.5 and 16 years of observations, respectively. The input data used in its elaboration are time series (weekly from satellite techniques and 24-h sessionwise from VLBI) of station positions and daily Earth Orientation Parameters (EOPs). The ITRF2008 origin is defined in such a way that it has zero translations and translation rates with respect to the mean Earth center of mass, averaged by the SLR time series. Its scale is defined by nullifying the scale factor and its rate with respect to the mean of VLBI and SLR long-term solutions as obtained by stacking their respective time series. The scale agreement between these two technique solutions is estimated to be $1.05 \pm 0.13 \mathrm{ppb}$ at epoch 2005.0 and $0.049 \pm 0.010 \mathrm{ppb} / \mathrm{yr}$. The ITRF2008 orientation (at epoch 2005.0) and its rate are aligned to the ITRF2005 using 179 stations of high geodetic quality. An estimate of the origin components from ITRF2008 to ITRF2005 (both origins are defined by SLR) indicates differences at epoch 2005.0, namely: $-0.5,-0.9$ and $-4.7 \mathrm{~mm}$ along $X, Y$ and $Z$-axis, respectively. The translation rate differences between the two frames are zero for $Y$ and $Z$, while we observe an $X$-translation rate of $0.3 \mathrm{~mm} / \mathrm{yr}$. The estimated formal errors of these parameters are $0.2 \mathrm{~mm}$ and $0.2 \mathrm{~mm} / \mathrm{yr}$, respectively. The high level of origin agreement between ITRF2008 and ITRF2005 is an indication of an imprecise ITRF2000 origin
\end{abstract}

Z. Altamimi $(\bowtie) \cdot X$. Collilieux $\cdot$ L. Métivier Institut Géographique National, LAREG,

6-8 Avenue Blaise Pascal, 77455 Marne-la-Vallée, France

e-mail: zuheir.altamimi@ign.fr

\section{Métivier}

Institut de Physique du Globe de Paris, Universite Paris-Diderot, Batiment Lamarck, case 7011, 35 rue Helene Brion, 75013 Paris, France that exhibits a $Z$-translation drift of $1.8 \mathrm{~mm} / \mathrm{yr}$ with respect to ITRF2005. An evaluation of the ITRF2008 origin accuracy based on the level of its agreement with ITRF2005 is believed to be at the level of $1 \mathrm{~cm}$ over the time-span of the SLR observations. Considering the level of scale consistency between VLBI and SLR, the ITRF2008 scale accuracy is evaluated to be at the level of $1.2 \mathrm{ppb}(8 \mathrm{~mm}$ at the equator) over the common time-span of the observations of both techniques. Although the performance of the ITRF2008 is demonstrated to be higher than ITRF2005, future ITRF improvement resides in improving the consistency between local ties in co-location sites and space geodesy estimates.

Keywords Reference systems · Reference frames - ITRF . Earth rotation

\section{Introduction}

Precisely determining satellite orbits or quantifying Earth rotation, tectonic plate motion or mean sea level rise and its variability in space and time fundamentally depend on the availability of a truly global Terrestrial Reference System (TRS) that only space geodesy is able to realize. Following the established terminology on reference systems (Kovalevsky et al. 1989), we distinguish between a TRS and its realization by a Terrestrial Reference Frame (TRF). The former is being ideal and conventional, with specified mathematical and physical properties, while the latter is constructed using space geodesy observations (hence with uncertainties) and is being accessible to the users through numerical values (e.g. positions as a function of time of a network of Earth crust-based points). The main physical and mathematical properties of a TRS (at the theoretical level) or of a TRF (at the realization level) are the origin, the scale, the orientation and their time evolution. 
The International Terrestrial Reference System (ITRS), realized and maintained by the International Earth Rotation and Reference Systems Service (IERS) has been formally adopted and recommended for Earth science applications (IUGG 2007). For more details regarding the ITRS description and definition, the reader may refer to Chapter 4 of the IERS Conventions (Petit and Luzum 2010). The ITRS realization, through the International Terrestrial Reference Frame (ITRF) is regularly updated to take into account not only new accumulated data, but also improved analysis strategies applied by the analysis centers of the contributed techniques. Eleven ITRF versions were hence published, starting with the ITRF88 and ending with ITRF2008 described in this article. The space geodetic techniques that contribute to the ITRF construction are Very Long Baseline Interferometry (VLBI), Satellite Laser Ranging (SLR), Global Navigation Satellite Systems (GNSS) and Doppler Orbitography Radiopositioning Integrated by Satellite (DORIS). These techniques are organized as scientific services within the International Association of Geodesy (IAG) and known by the IERS as Technique Centers (TCs): the International VLBI Service (IVS), (Schlüter and Behrend 2007), the International Laser Ranging Service (ILRS), (Pearlman et al. 2002), the International GNSS Service, formerly the International GPS Service (IGS), (Dow et al. 2009) and the International DORIS Service (IDS), (Willis et al. 2010).

Although ITRF2005 (Altamimi et al. 2007) was an improved solution compared to past ITRF versions, in terms of internal consistency and robustness, it, however, shed light on some deficiencies of the four technique solutions as well as their co-locations. In preparation for the ITRF2008, the IAG technique services, together with their respective Analysis and Combination Centers invested considerable effort to improve their solutions. Without being exhaustive, we can cite that the reprocessed IGS solution involves new absolute phase center offsets and variations models for satellites and stations (Schmid et al. 2007) and a new tropospheric model (Boehm et al. 2006a, 2007); the reanalysis solution from IVS accounts for the mean pole tide correction following the IERS Conventions (Petit and Luzum 2010) and a more advanced troposphere modeling (Boehm et al. 2006b) and corrections for antenna thermal deformations (Nothnagel 2009); the improved ILRS solution takes into account new range bias values, a new tropospheric modeling (Mendes et al. 2002; Mendes and Pavlis 2004) and other station-dependent corrections, and for the first time the DORIS combined solution involves seven IDS Analysis Centers (Valette et al. 2010).

Each time an ITRF solution is prepared, one of the fundamental aspects of its formation is to ensure the optimal frame definition and its stability as a function of time. While the origin and the scale (having physical properties) are critical parameters of interest to Earth science applications, the orientation and its time variation (arbitrary and conventionally defined) are of importance to ensure the continuity of Earth rotation determination. Any bias or drift in these components will inevitably propagate into the geophysical results that depends on the usage of the ITRF, as for instance mean sea level assessment and its variability in space and time (Morel and Willis 2005; Beckley et al. 2007; Collilieux and Wöppelmann 2010). As it will be shown by the discussion of the ITRF2008 results, the current achievable accuracy of the ITRF scale is probably not better than 1 part-per-billion (ppb) and its temporal stability at the range of $0.05 \mathrm{ppb} / \mathrm{yr}$. The total error budget includes systematic errors of not only VLBI and SLR, but also GPS that is crucially needed to tie the three other techniques together, as well as local tie errors.

The space geodetic technique solutions and local ties at co-location sites used to generate ITRF2008 are first presented in Sect. 2. Section 3 describes the combination strategy that has been applied to these data. The output results of this combination and ITRF2008 quality evaluation are described in Sect. 4. The main ITRF2008 results and performance are synthesized in the conclusion.

All the ITRF2008 files and results are available at the ITRF web site: http://itrf.ign.fr/ITRF_solutions/2008/

\section{ITRF2008 input data}

As for any ITRF solution, the ITRF2008 relies not only on space geodesy solutions, but also on local ties at co-location sites. In the following two sub-sections we describe the two sets of data used in the ITRF2008 construction.

\subsection{Space geodesy solutions}

We recall that the ITRF input time series solutions are provided on a weekly basis by the IAG International Services of satellite techniques: IGS, ILRS and IDS and on a daily (VLBI session-wise) basis by the IVS. Each per-technique time series is already a combination of the individual Analysis Center (AC) solutions of that technique. Table 1 summarizes the submitted solutions by the IAG services, specifying the time span, solution type and the constraints applied by the TCs as well as the estimated Earth Orientation Parameters (EOPs). For more details regarding the type of constraints applied by the techniques, and the minimum constraints concept in general, the reader may refer to Dermanis (2000, 2003); Sillard and Boucher (2001); Altamimi et al. (2002a, 2004) or to Chapt. 4 of the IERS Conventions (Petit and Luzum 2010). The submitted VLBI solution involves more than 4,000 session-wise SINEX files spanning the entire VLBI observation history (Bockmann et al. 2010). The SLR solution covers also its full observation history, and comprises fortnightly SINEX files, with polar motion and Length of Day (LOD) estimated each three days between 1983.0 and 
Table 1 Summary of submitted solutions to ITRF2008

\begin{tabular}{lllll}
\hline TC & Data-span & Solution type & Constraints & EOPs \\
\hline IVS & $1980.0-2009.0$ & Normal equation & None & Polar motion, rate, LOD, UT1-UTC \\
ILRS & $1983.0-2009.0$ & Variance-covariance & Loose & Polar motion, LOD \\
IGS & $1997.0-2009.5$ & Variance-covariance & Minimum & Polar motion, rate, LOD \\
IDS & $1993.0-2009.0$ & Variance-covariance & Minimum & Polar motion, rate, LOD \\
\hline
\end{tabular}

1993.0 and weekly SINEX files with daily polar motion and LOD estimates afterwards (Pavlis et al. 2010). The GPS submitted solution represents a large part of the first reprocessed solution by the IGS and covers the time period 1997.0 2009.5 (Ferland 2010; Ferland and Piraszewski 2008). Note that a very small portion of GLONASS observations were used by some IGS ACs that contributed to the reprocessing effort. For the first time the DORIS contribution is a combined time series involving seven ACs and covers its full observation history, using data from all available satellites with onboard DORIS receiver, except Jason-2 (Valette et al. 2010).

The ITRF2008 network comprises 934 stations located at 580 sites, with 463 sites in the northern hemisphere and 117 in the southern hemisphere. The ITRF2008 combination involves 84 co-location sites where two or more technique instruments were or are currently operating and for which local ties are available. Figure 1 illustrates the full ITRF2008 network where we superimposed the VLBI, SLR and DORIS sites co-located with GPS. In fact all the 84 co-location sites comprise permanent GPS stations, except two sites: Dionysos (Greece) where DORIS and an old mobile SLR were co-located, and Richmond (Virginia, USA) where VLBI, SLR and DORIS systems were co-located.

\subsection{Local ties in co-location sites}

The local ties used in the ITRF2008 combination are provided in SINEX format with known measurement epochs, and $63 \%$ of them are available with full variance covariance information. Most of the local ties used in the ITRF2005 combination are used here with some updates, e.g., Tahiti (GPS, SLR, DORIS), Tsukuba (GPS, VLBI), Herstmonceux (GPS, SLR), Medicina and Noto (GPS, VLBI), Greenbelt (GPS, VLBI, SLR, DORIS), Maui/ Haleakala (GPS, SLR), San Fernando (GPS, SLR), Onsala (GPS, VLBI). Most of

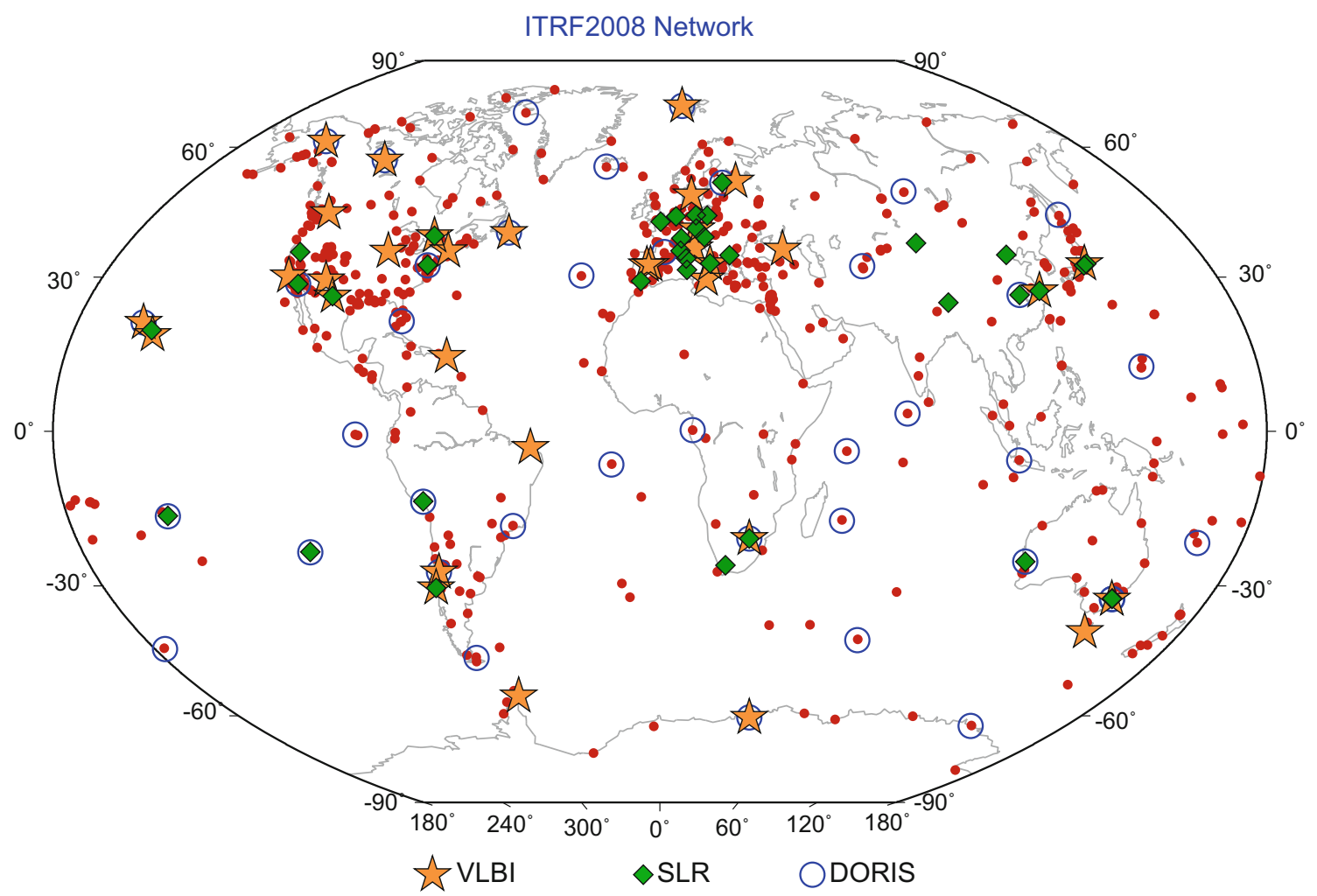

Fig. 1 ITRF2008 network highlighting VLBI, SLR and DORIS sites co-located with GPS 
the local tie SINEX files were provided by the national agencies operating co-location sites, all sites in Australia (Johnston and Dawson 2004); three sites in Italy: Medicina, Noto (Sarti et al. 2004) and Matera (Bianco 2006); Wettzell and Concepcion (Schlüter et al. 2004a,b); Tsukuba (GSI 2010); Onsala (Haas 2010); and all the DORIS co-location sites were re-adjusted by the IGN survey department in order to generate full SINEX files, using the most recent surveys operated at these sites. All the local tie SINEX files used in the ITRF2008 combination are available at http://itrf.ign.fr/local_surveys. php.

Counting the number of co-locations between VLBI, SLR and DORIS, taken by pairs, we find eight VLBI-SLR, ten VLBI-DORIS and ten SLR-DORIS. These are very poor numbers of co-locations to allow a reliable combination of these three techniques alone. Therefore, the GPS is playing a major role in the ITRF combination by linking together the three other techniques (Altamimi and Collilieux 2009). We count in total 137 tie vectors between GPS and the three other techniques: 44 for VLBI, 48 for SLR and 45 for DORIS. 15 additional ties were also used between old and current DORIS beacon reference points in DORIS-only sites.

\section{ITRF2008 data analysis}

The CATREF combination model used for the ITRF combination is extensively described in previous publications and in particular (Altamimi et al. 2002b, 2007). For the ITRF2008 generation, we followed the same analysis strategy used for the ITRF2005 combination (Altamimi et al. 2007). We recall here that two steps are currently used for the ITRF construction: (1) stacking the individual time series to estimate a longterm solution per technique comprising station positions at a reference epoch, velocities and daily EOPs; and (2) combining the resulting long-term solutions of the four techniques together with the local ties in co-location sites. The main two equations of the combination model are given below for completeness. They involve a 14-parameter similarity transformation, station positions and velocities and EOPs and are written as

$$
\begin{aligned}
& \left\{\begin{aligned}
X_{s}^{i}= & X_{c}^{i}+\left(t_{s}^{i}-t_{0}\right) \dot{X}_{c}^{i} \\
& +T_{k}+D_{k} X_{c}^{i}+R_{k} X_{c}^{i} \\
& +\left(t_{s}^{i}-t_{k}\right)\left[\dot{T}_{k}+\dot{D}_{k} X_{c}^{i}+\dot{R}_{k} X_{c}^{i}\right] \\
\dot{X}_{s}^{i}= & \dot{X}_{c}^{i}+\dot{T}_{k}+\dot{D}_{k} X_{c}^{i}+\dot{R}_{k} X_{c}^{i}
\end{aligned}\right. \\
& \begin{cases}x_{s}^{p} & =x_{c}^{p}+R 2_{k} \\
y_{s}^{p} & =y_{c}^{p}+R 1_{k} \\
U T_{s} & =U T_{c}-\frac{1}{f} R 3_{k}\end{cases} \\
& \dot{x}_{s}^{p}=\dot{x}_{c}^{p} \\
& \dot{y}_{s}^{p}=\dot{y}_{c}^{p} \\
& L O D_{s}=L O D_{c}
\end{aligned}
$$

where for each point $i, X_{s}^{i}$ (at epoch $t_{s}^{i}$ ) and $\dot{X}_{s}^{i}$ are positions and velocities of technique solution $s$ and $X_{c}^{i}$ (at epoch $\left.t_{0}\right)$ and $\dot{X}_{c}^{i}$ are those of the combined solution $c$. For each individual frame $k$, as implicitly defined by solution $s, D_{k}$ is the scale factor, $T_{k}$ the translation vector and $R_{k}$ the rotation matrix. The dotted parameters designate their derivatives with respect to time. The translation vector $T_{k}$ is composed of three origin components, namely $T_{x}, T_{y}, T_{z}$ and the rotation matrix of three small rotation parameters: $R_{x}, R_{y}, R_{z}$, following the three axes, respectively $X, Y, Z$. $t_{k}$ is a conventionally selected epoch of the seven transformation parameters. In addition to Eq. (1) involving station positions (and velocities), the EOPs are added by Eq. (2), following (Zhu and Mueller 1983), making use of pole coordinates $x_{s}^{p}, y_{s}^{p}$ and universal time $U T_{s}$ as well as their daily rates $\dot{x}_{s}^{p}, \dot{y}_{s}^{p}$ and $L O D_{s}$. The link between the combined frame and the EOPs is ensured via the three rotation parameters appearing in the first three lines of Eq. (2).

Note that Eq. (1) uses the linearized form of the general similarity transformation formula, neglecting second and higher order terms. For more details regarding the mathematical derivation of Eq. (1), the reader may refer to Chapt. 4 of the IERS Conventions (Petit and Luzum 2010), and to Altamimi and Dermanis (2010).

The reader should note that in past publications, e.g., (Altamimi et al. 2007), we considered the three last lines of Eq. (2) as the time derivatives of the first three lines of the same equation, and so rotation rate terms have been added. However, the conventional EOP representation provided by the techniques is in the form of daily offset (at noon) and drift (or rate), while other types of EOP representation could also be considered, such as continuous piece-wise linear function where no EOP rates would appear. Therefore, the daily EOP rates are independent from the orientation time evolution of the reference frame, although they should be correlated with the daily EOP offset values. In case of time series stacking, the addition of such rotation rates has no impact on the results because they are not introduced in the normal equation. However, their addition in case of combining long-term solutions (which contain EOPs) yields biased frame rotation rates of the individual solutions with respect to (but without altering) the combined frame.

\subsection{ITRF2008 time series analysis}

The first line of Eq. 1 and the entire Eq. 2 are used to estimate long-term solutions for each technique, by accumulating (rigorously stacking) the individual technique time series of station positions and EOPs. In this process, the second line of Eq. 1 and the rates of the translation, scale and rotation parameters are not included because station velocities are not available/estimable at the weekly (daily) basis. Moreover, a precise definition of the reference frame associated with the 
resulting long-term solution (comprising station positions at a reference epoch, station velocities and EOPs) has to be clearly specified. As transformation parameters are estimated between each weekly (or session-wise) frame and the long-term frame, it becomes necessary to define the longterm frame origin, scale, orientation and their time evolution and therefore to complete the rank deficiency of the constructed normal equation. It is essential that the longterm solutions be representative of the mean origin and mean scale information of the space geodesy techniques. The particular type of minimal constraints introduced in Altamimi et al. (2007) have been designed for such purpose and are consequently used here to preserve the long-term solution origin (for SLR and DORIS) and scale (for VLBI, SLR and DORIS). As the input GPS weekly frames have been explicitly expressed in the IGS05 (derived from ITRF2005), GPS long-term solution has been expressed with respect to ITRF2005 and was not used for the ITRF2008 origin and scale definition.

One of the main advantages of using time series as input data for the ITRF combination is the ability to identify station position discontinuities which are mostly due to earthquakes and equipment changes. There are in total 638 discontinuities; 550 of them are GPS-related. In the generation of the long-term technique solutions, we consider different station positions before and after each event. Nearby stations within the same site and multiple segments (in case of discontinuities) are constrained to have the same velocity, except for sites where geophysical events such as large earthquakes occur.

As a by-product of the time series analysis we evaluate the internal precision (or repeatability) of each technique solution, through the computation of the Weighted Root Mean Scatter (WRMS) over the time series of weekly or daily residuals. Figure 2 displays the WRMS in East, North and Up components of the four technique solutions submitted to ITRF2008, with respect to the estimated long-term solutions. We computed the median values of these WRMS for the four technique solutions over the three components which are for GPS: 1.6, 1.7 and 4.4; for VLBI: 2.9, 3.0 and 7.4; for SLR: 7.9, 9.4, 7.9 and for DORIS: $11.9,10.9$ and $13.3 \mathrm{~mm}$ over the East, North and Up components, respectively. These median values are representative of the intrinsic precision (or repeatability) of each technique solution computed using the full time series, including the early less-precise observations, as well as all (less and well performing) stations. An inspection of the WRMS plotted in Fig. 2 indicates a precision improvement in the three components at recent dates for GPS, SLR and DORIS. It is interesting to note that for DORIS in particular the precision improves when observations from four to five satellites are used.

Seasonal signals can be noticed in the WRMS time series, and in particular for GPS. It has been shown that some of these variations, especially the annual, are related to loading effects (Altamimi and Collilieux 2009). Indeed, the Earth is continuously deforming due to non-tidal loading effects
Fig. 2 WRMS (internal precision) of weekly (or session-wise for VLBI) station position time series with respect to the long-term solution along the East, North and the Height components for GPS (top left); VLBI (top right); DORIS (bottom left) and SLR (bottom right). For DORIS, the number of satellites used is indicated on the plot
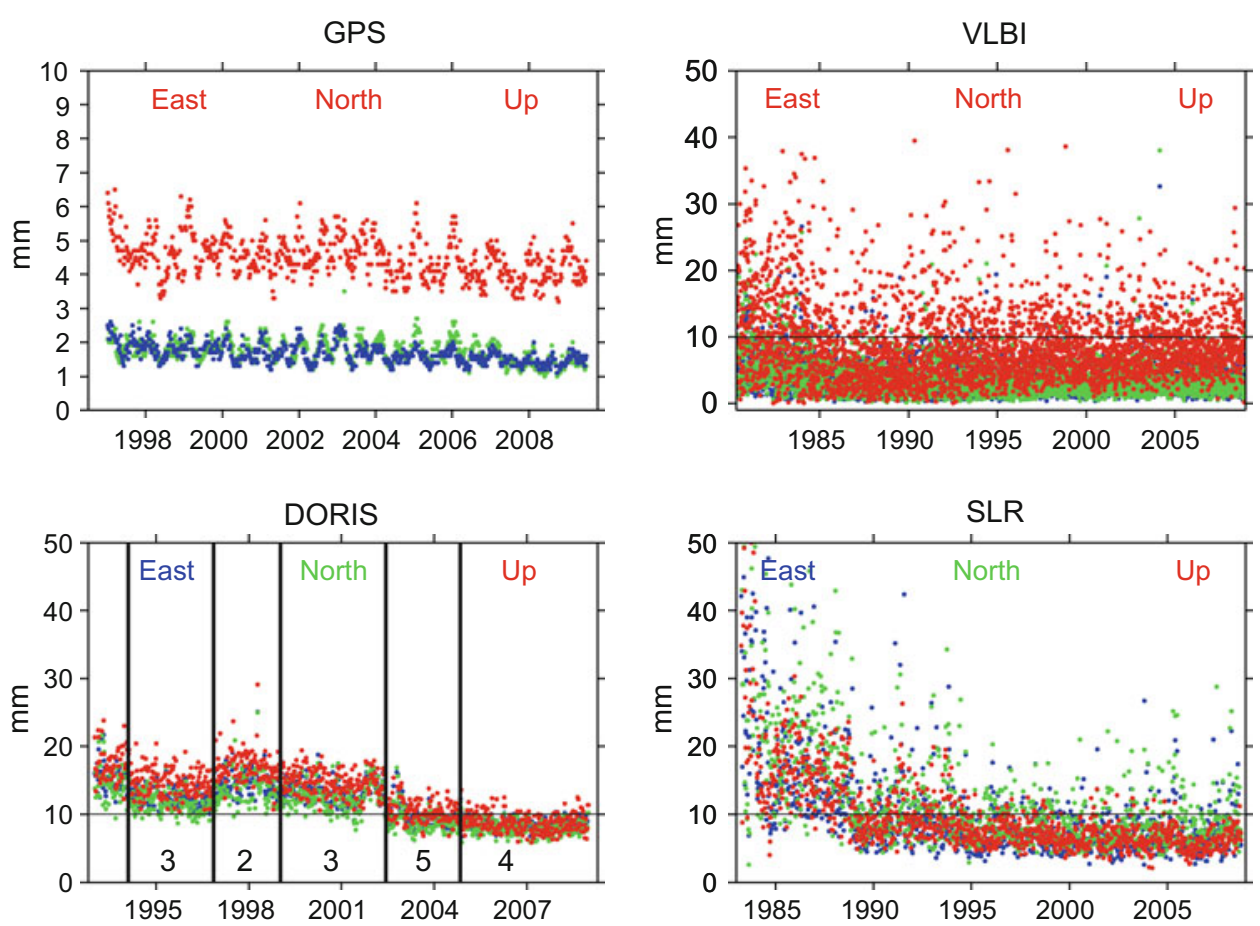
(Farrell 1972) but modeling of these phenomena is not yet integrated in the processing of geodetic observables for all the effects and all the techniques. It was decided not to incorporate the modeling of any non-tidal loading effects in the processing of geodetic data submitted by the TCs since not all available loading models have been fully evaluated. For instance, it was discovered recently that neglecting high-resolution topography changes induce errors in the atmospheric loading models (van Dam et al. 2010). However, it is worth noting that loading effects are not expected to affect ITRF frame parameters, especially the origin and scale (Collilieux et al. 2010), although the coordinates of the stations with few observations are impacted by this neglected effect. Therefore for the future, it becomes necessary that loading models, if they are accurate enough, be recommended by the IERS to be homogeneously and consistently used by the four techniques, since neglected effects, as the atmospheric tides, may be aliased into low frequencies signals (Tregoning and Watson 2009).

\subsection{ITRF2008 multi-technique combination}

The second step of the ITRF2008 analysis consists in combining the long-term solutions of the four technique solutions together with local ties at co-location sites. The ITRF2008 is specified by the following frame parameters:
- Origin: The ITRF2008 origin is defined in such a way that there are null translation parameters at epoch 2005.0 and null translation rates with respect to the ILRS SLR time series.

- Scale: The scale of the ITRF2008 is defined in such a way that there are null scale factor at epoch 2005.0 and null scale rate with respect to the mean scale and scale rate of VLBI and SLR time series.

- Orientation: The ITRF2008 orientation is defined in such a way that there are null rotation parameters at epoch 2005.0 and null rotation rates between ITRF2008 and ITRF2005. These two conditions are applied over a set of 179 reference stations located at 131 sites as illustrated by Fig. 3. The reference sites include 107 GPS, 27 VLBI, 15 SLR and 12 DORIS.

Special attention was devoted to the important issue of relative weighting of the space geodesy technique solutions and local ties. Several test combinations were performed by varying the weighting of all input data solutions in order to reach and adopt a statistically satisfactory ITRF2008 combination. The weighting of the individual solutions is operated by estimating an appropriate variance factor per data set and iterating as necessary. Because of the imbalance between the space geodesy technique solutions (which are global by nature)

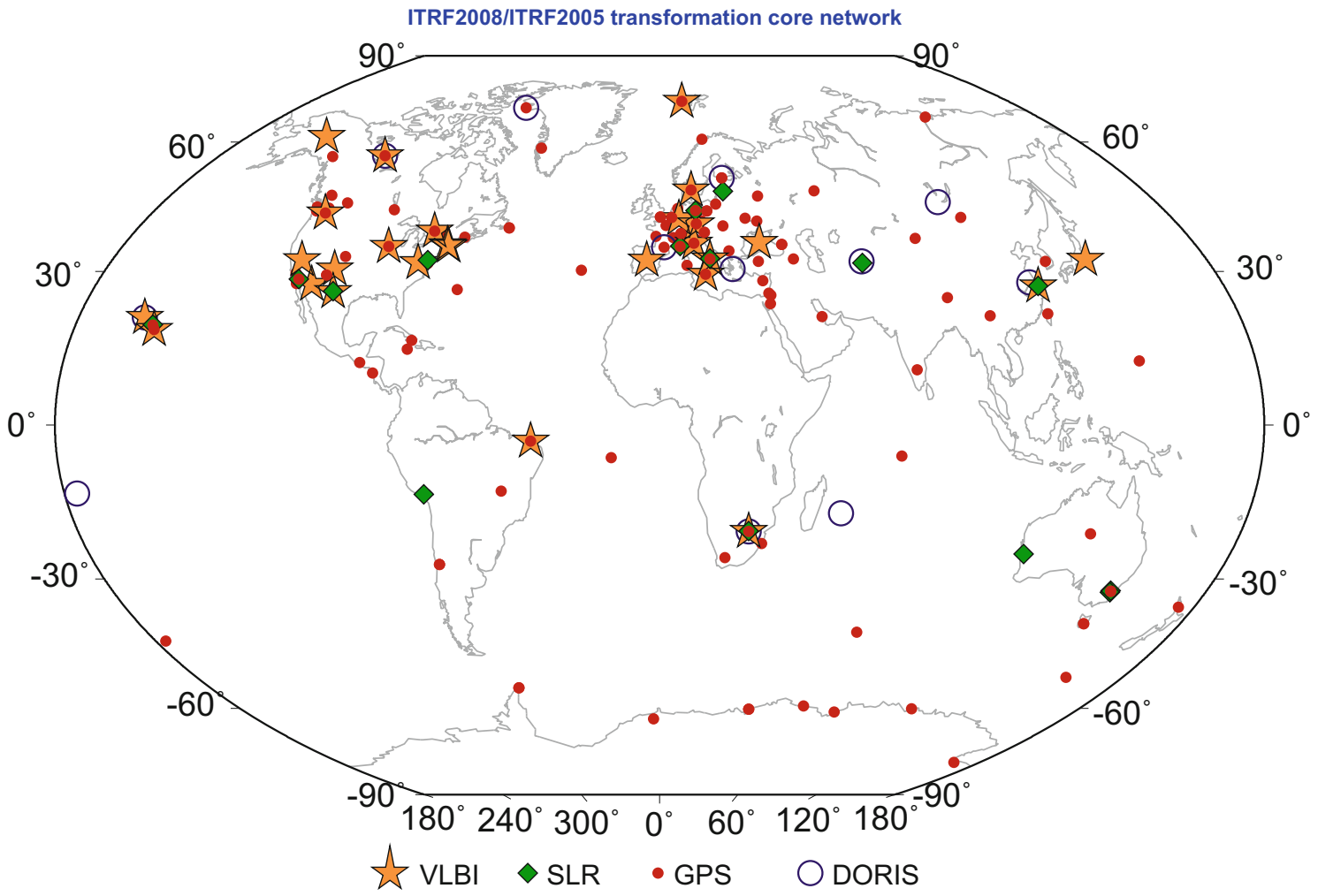

Fig. 3 Location of the core sites used in the estimation of the 14 transformation parameters between ITRF2008 and ITRF2005 and their orientation alignment 
and the small, local-by-nature networks of co-location sites, it is very difficult to adequately use a mathematically or statistically prescribed method of variance component estimation as the degree of freedom or Helmert methods (Bähr et al. 2007). Therefore, the overall weighting process used in the ITRF2008 combination is a mixture of the degree of freedom method as described in (Altamimi et al. 2002b), Appendix A, Sect. A5, Eq. A16 and an empirical weighting. The long-term solutions of the four techniques are first properly weighted as a function of the variance factors (VF) obtained during the process of the individual stacking of the technique time series and computed as

$V F=\frac{\sum_{s}^{S} v_{s}^{T} P_{s} v_{s}}{f}$

where $v_{s}$ is the vector of the station coordinates post fit residuals of solution $s, P_{s}$ its weight matrix (the inverse of the variance-covariance matrix) and $S$ is the total number of solutions included in the stacking. $f$ is the number of degrees of freedom of the least squares adjustment, which is equal to the difference between the number of observations and the number of unknowns. Being a function of the residuals, normalized by the weight matrices, the VF is considered as a statistical indicator of the overall quality of the combination. Adequately weighting the individual solutions should lead to a variance factor close to unity. Therefore, an increase of the VF is a strong indication of the increase of the normalized residuals (raw residuals divided by their observation a priori errors), implying an inappropriate weighting of the individual solutions included in the combination or/and large outliers.

From this first step analysis, the following individual variance factors were obtained: 0.69 for GPS, 2.95 for SLR, 3.37 for VLBI and 2.20 for DORIS, respectively. As results of several ITRF2008 multi-technique test combinations, it was necessary to rescale the variance factors of VLBI and DORIS, by 1.2 and 2.5 , respectively. In order to judge the appropriateness of this weighting scheme, we performed three main test combinations: a combination of the four technique velocity fields (downweighting station positions and local ties), and two combinations with and without EOPs. The obtained global variance factors of unit weight are in all cases close to unity, with variations less than $10 \%$.

In the ITRF combination, local ties at co-location sites, provided in SINEX format, are used as observations with proper weighting as described in detail in Altamimi et al. (2002b). An empirical variance factor per local tie SINEX file is estimated during the combination process in such a way that (1) the normalized residual should not exceed a threshold of 3 and (2) the uncertainty per tie vector component should not be below $3 \mathrm{~mm}$. The reasons for these two conditions are that (1) we believe a local tie between physically inaccessible instrumental measurement reference points is unlikely to be precise to better than $3 \mathrm{~mm}$, and (2) the agreement between local ties and space geodesy estimates are by far larger than $3 \mathrm{~mm}$ for most of the co-location sites and consequently (3) the local ties should be properly weighted in order to avoid contaminating the combined frame defining parameters by local tie and space geodesy discrepancies and at the same time to preserve consistency between individual technique solutions and ITRF2008. However, the discrepancies mean that either local ties or space geodesy estimates (or both) are imprecise or in error. One of the local survey difficulties is to precisely determine the eccentricity between the intersection of axes of VLBI or SLR telescopes and the ground physical markers. As an example, Sarti et al. (2009) estimated that the action of gravity on the structure of the Medicina (Italy) VLBI antenna biases the estimate of the instrument's reference point up to $1 \mathrm{~cm}$.

A detailed analysis of the consistency between local ties and space geodesy estimates is discussed in Sect. 4.5.

\section{ITRF2008 results}

In the following subsections we discuss the main results of the ITRF2008 analysis as obtained from the two steps: time series stacking and multi-technique combination.

\subsection{ITRF2008 origin}

The submitted ILRS SLR solution was used to define the ITRF2008 origin, by fixing to zero (and consequently eliminating from the normal equation) the six parameters (translations and rates) of its corresponding long-term cumulative solution. Figure 4 illustrates the temporal behavior of the weekly SLR origin components with respect to ITRF2008, showing as expected (Dong et al. 1997) seasonal variations, but no shift or drift are visible. In order to evaluate the performance of the SLR origin determination, it is then important to compare the origin components between ITRF2008 and ITRF2005. An estimate of the translation components from ITRF2008 to ITRF2005 indicates differences at epoch 2005.0, namely $-0.5,-0.9$ and $-4.7 \mathrm{~mm}$ along $X, Y$ and $Z$-axes, respectively. The translation rate differences are zero for $Y$ and $Z$, while we observe an $X$-translation rate of $0.3 \mathrm{~mm} / \mathrm{yr}$. These numbers suggest that the origin agreement between the two frames is at the level of or better than one centimeter over the entire time span of the SLR observations, and may be regarded as the level of the origin accuracy achievable today. We recall that there is a significant $Z$-translation rate of $1.8 \mathrm{~mm} / \mathrm{yr}$ between ITRF2000 and ITRF2005 (Altamimi et al. 2007). A few studies (Greff-Lefftz 2000; Greff-Lefftz et al. 2010; Métivier et al. 2010) have shown that geophysical phenomena, such as present day ice melting or postglacial rebound, cannot lead to an 

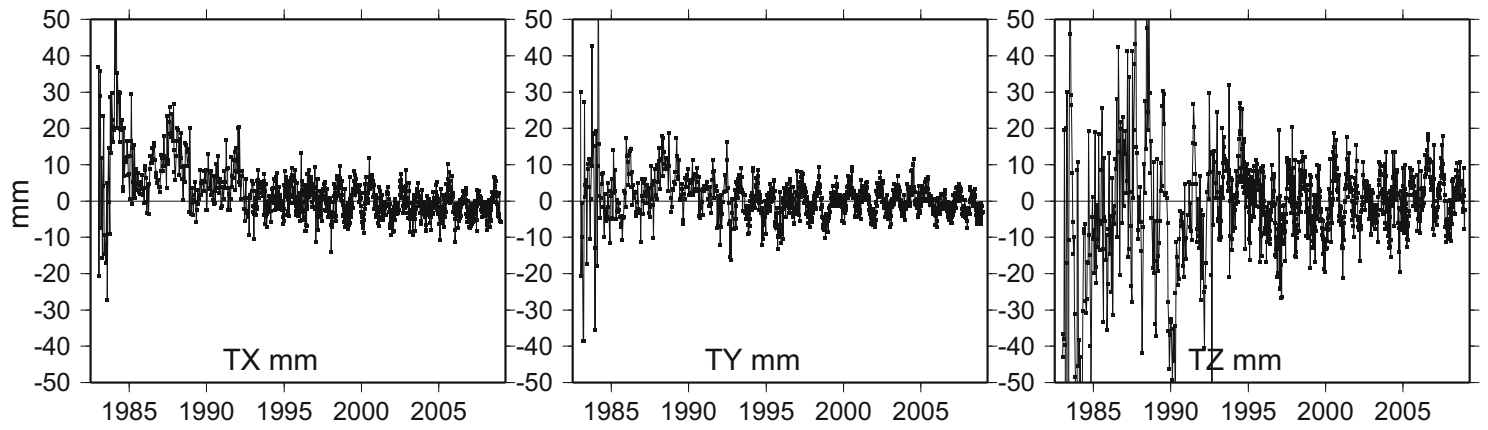

Fig. 4 Weekly translation components of the SLR ILRS solution with respect to ITRF2008, in millimeter along the $X, Y$ and $Z$-axes: left, middle and right, respectively
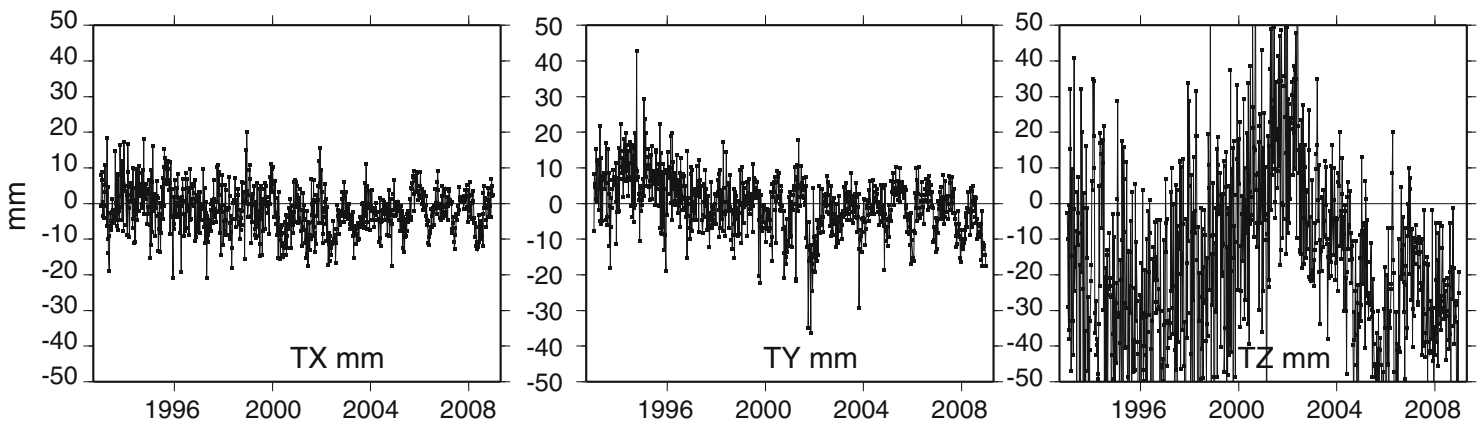

Fig. 5 Weekly translation components of the DORIS IDS-3 solution with respect to ITRF2008, in millimeter along the $X, Y$ and $Z$-axes: left, middle and right, respectively

increase of the geocenter velocity along the $Z$-axis larger than $0.3 \mathrm{~mm} / \mathrm{yr}$ in a decade. Given the fact that the ITRF2008 results show negligible translation rates with respect to ITRF2005, the Z-translation rate between ITRF2005 and ITRF2000 is most likely an indication of an imprecise origin determination of the ITRF2000 solution. This statement is also supported by the fact that both ITRF2005 and ITRF2008, being based on rigorous time series analysis, are by far more precise than ITRF2000.

While detailed analyses of the IDS submitted solution to ITRF2008 were published in (Altamimi and Collilieux 2010; Valette et al. 2010), for completeness Fig. 5 illustrates the temporal origin components of the DORIS IDS-3 solution with respect to ITRF2008. This plot shows a rather stable Tx, a slope change in Ty after 2002.0 and a very scattered Tz behavior.

\subsection{ITRF2008 scale}

The level of agreement of the scale and scale rate between VLBI and SLR solutions used in the ITRF2005 combination were $1.4( \pm 0.11) \mathrm{ppb}$ at epoch 2005.0 and $0.08( \pm 0.01)$ $\mathrm{ppb} / \mathrm{yr}$, respectively. This low level of consistency was due to several factors, including uncorrected mean pole tide effect of the VLBI and probably station range biases of the SLR, together with their poor co-locations and the degradation of their network with time.

As results from the final ITRF2008 combination we found that the scale and scale rate agreement between VLBI and SLR solutions are $1.05( \pm 0.13) \mathrm{ppb}$ at epoch 2005.0 and $0.049( \pm 0.010) \mathrm{ppb} / \mathrm{yr}$, respectively. This indicates an improvement compared to the past ITRF2005 results. This improvement is particularly due to the reprocessing effort of both IVS and ILRS. In addition, for some SLR co-located stations, we introduced breaks in the time series to account for significant discontinuities which improved the agreement of the estimated vertical velocities with GPS and consequently the scale rate agreement with VLBI. Propagating the scale discrepancy between SLR and VLBI at the start and end epochs of the time-span of VLBI data leads to a maximum discrepancy of $1.2 \mathrm{ppb}$ ( $8 \mathrm{~mm}$ at the equator), which could be considered as the level of the scale accuracy achievable today. Therefore, defining the ITRF2008 scale to be in the middle of both technique solutions is the most appropriate choice that minimizes the scale impact for these two techniques when using the ITRF2008 products.

Figure 6 illustrates the daily scales of VLBI, and weekly scales of SLR and DORIS solutions with respect to ITRF2008 using the full time series. From that figure, we can distinguish 
the level of agreement, scattering and temporal behavior of the scale factors of the three techniques. The estimated uncertainties (formal error at one sigma) of the scale and scale rates as results from the ITRF2008 combination are $0.10,0.13,0.19 \mathrm{ppb}$ at epoch 2005.0 and $0.01,0.01$ and $0.03 \mathrm{ppb} / \mathrm{yr}$ for VLBI, SLR and DORIS, respectively.

The scale factor of the DORIS IDS-3 solution with respect to ITRF2008 is $0.70 \mathrm{ppb}$ at epoch 2005.0 , and so it is closer to VLBI than to SLR. As discussed in (Altamimi and Collilieux 2010), IDS-3 has a fairly stable scale (with negligible drift) during 1993-2002, and then displays uneven non-linear behavior afterward. This behavior is most likely to be related to the change of the number of satellites used.

\subsection{Origin and scale seasonal variations}

In order to evaluate the origin and scale seasonal variations visible in the time series plotted in Figs. 4, 5 and 6, we fitted annual amplitudes and phases (listed in Table 2) to the SLR and DORIS translation and scale components as well as to the scale of VLBI. For comparison, Table 2 reproduces also the values which were obtained using ITRF2005 data, published in (Altamimi et al. 2007). We restrict our discussion here to the quantification of the apparent geocenter motion and scale seasonal variation. The variations of the translation time series derived from the satellite techniques are expected to be close to the opposite of the non-linear part of the geocenter motion (Collilieux et al. 2009). The difference between the "true" geocenter motion and the translation
Fig. 6 Scale factors, in millimeters, of the VLBI, SLR and DORIS solutions with respect to ITRF2008
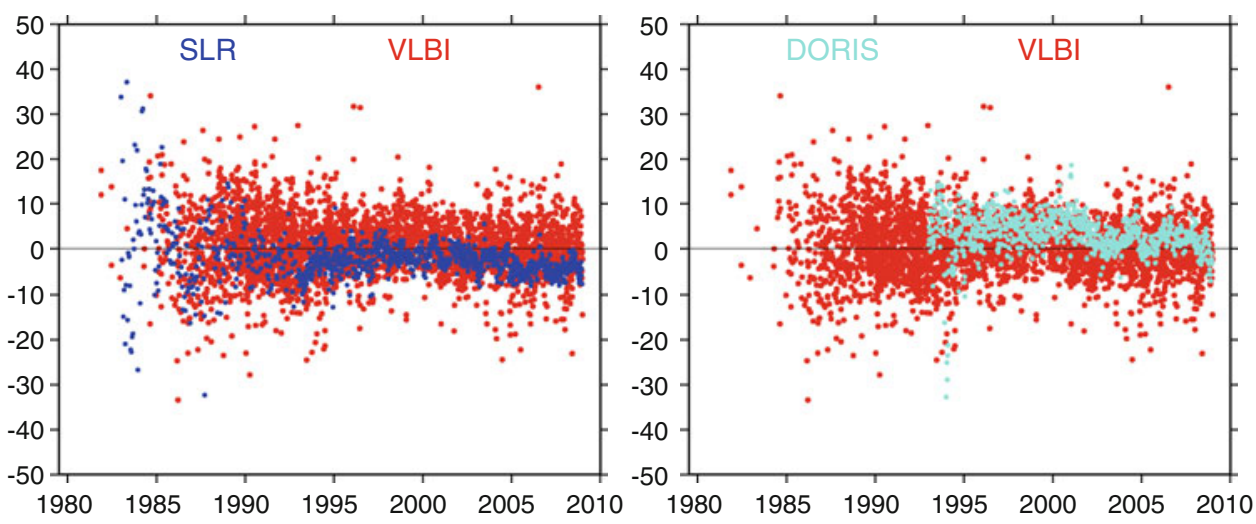

Table 2 Annual amplitude $(A)$ and phase $(\phi)$ of the translation components and scale factor, according to the model $A \cos (\omega \cdot t-\phi)$ with $t$ in decimal year

\begin{tabular}{|c|c|c|c|c|c|c|c|c|}
\hline \multirow[t]{2}{*}{$\mathrm{TC}$} & \multicolumn{2}{|l|}{$\mathrm{TX}$} & \multicolumn{2}{|l|}{ TY } & \multicolumn{2}{|l|}{$\mathrm{TZ}$} & \multicolumn{2}{|l|}{ scale } \\
\hline & $\overline{A(\mathrm{~mm})}$ & $\overline{\phi(\mathrm{deg})}$ & $\overline{A(\mathrm{~mm})}$ & $\overline{\phi(\mathrm{deg})}$ & $\overline{A(\mathrm{~mm})}$ & $\overline{\phi(\operatorname{deg})}$ & $\overline{A(\mathrm{~mm})}$ & $\phi(\mathrm{deg})$ \\
\hline \multicolumn{9}{|l|}{ ITRF2008 } \\
\hline IVS & - & - & - & - & - & - & 2.2 & 241 \\
\hline \pm & & & & & & & 0.1 & 3 \\
\hline ILRS & 2.6 & 222 & 3.1 & 135 & 5.5 & 202 & 0.6 & 255 \\
\hline \pm & 0.1 & 3 & 0.1 & 2 & 0.3 & 10 & 0.1 & 10 \\
\hline IDS & 3.9 & 327 & 4.6 & 160 & 4.4 & 115 & 0.3 & 206 \\
\hline \pm & 0.2 & 3 & 0.3 & 3 & 1.1 & 14 & 0.1 & 27 \\
\hline \multicolumn{9}{|c|}{ ITRF2005 (Altamimi et al. 2007) } \\
\hline IVS & - & - & - & - & - & - & 2.7 & 220 \\
\hline \pm & & & & & & & 0.1 & 3 \\
\hline ILRS & 3.0 & 216 & 3.3 & 147 & 2.5 & 186 & 1.7 & 231 \\
\hline \pm & 0.2 & 4 & 0.2 & 3 & 0.4 & 11 & 0.2 & 7 \\
\hline IDS-IGN & 5.8 & 351 & 4.6 & 117 & 29.0 & 165 & 4.5 & 161 \\
\hline \pm & 0.5 & 5 & 0.5 & 6 & 2.5 & 5 & 0.3 & 4 \\
\hline IDS-LCA & 5.4 & 329 & 2.1 & 46 & 12.0 & 165 & 2.4 & 248 \\
\hline \pm & 0.5 & 5 & 0.5 & 13 & 1.8 & 9 & 0.4 & 9 \\
\hline
\end{tabular}


variations includes not only systematic errors related to orbit mis-modeling but also the aliasing of the loading effects (network effect) into the translation components (Collilieux et al. 2009; Lavallée et al. 2006). Scale annual variations also partly reflect this aliasing and can be interpreted as the mean vertical motion of the network (Collilieux et al. 2010). As all the geodetic networks are different, there is no reason to expect identical signals for all the techniques in the scale factor time series.

Comparing the annual amplitudes and phases of the SLR translations with those of ITRF2005 published in (Altamimi et al. 2007), we notice very similar estimates (i.e. within the uncertainties), except for the Z-translation amplitude which is two times larger here $(5.5 \mathrm{~mm})$. We checked that this $Z$-translation high amplitude is not significantly influenced by the pre 1993 SLR scattered data, being determined with only one satellite (Lageos 1). Contrariwise, while the SLR scale phase is statistically similar to ITRF2005 result, the amplitude here is smaller by $1 \mathrm{~mm}$. Compared to ITRF2005 results, the VLBI scale factor annual phase is changed by about $20^{\circ}$ and its annual amplitude is smaller by $0.5 \mathrm{~mm}$, but this difference may be explained by the modeling of the antenna thermal deformation (Bockmann et al. 2010). Regarding DORIS, we note a more realistic annual amplitude in the $Z$ component $(4.4 \mathrm{~mm})$, compared to the very large values exhibited by the two solutions used in the ITRF2005. This improvement is most likely to be related to the improvement of the solar radiation pressure treatment by some IDS analysis centers, leading to better estimate of the $Z$-geocenter (Gobindass et al. 2009). The DORIS $X$ and $Y$ amplitudes are higher by $1.5 \mathrm{~mm}$ than SLR, while only the phase in $Y$ is closer to SLR. The DORIS scale annual amplitude is very small $(0.3 \mathrm{~mm})$, but the DORIS network has also the most homogeneous distribution over the Earth surface.

\subsection{Impact of local ties on the ITRF2008 combination}

Given the importance of local ties in the ITRF combination, we chose here to evaluate their impact on one of the most critical estimated parameters, namely the scale, being determined for the ITRF2008 by the mean of VLBI and SLR solutions. For this purpose, we performed different combination tests whose results are listed in Table 3 . We evaluate the quality of these tests by discussing the obtained scale bias between VLBI and SLR solutions, as well as the variance factor of each adjustment. In reference to Eq. (3), an increase of the variance factor is the consequence of the increase of the normalized residuals (discrepancies between space geodesy estimates and local ties), implying an inappropriate relative weighting between space geodesy solutions and local ties.

Table 3 displays for each test, the scale factors (at epoch 2005.0) of SLR, GPS and DORIS with respect to VLBI solution, the global variance factor of each adjustment and the different cases of local ties handling. The first line of Table 3 lists the results of the final ITRF2008 combination where all available local tie SINEX files were properly weighted. Note that $63 \%$ of the local tie SINEX files are available with full variance-covariance information. The second combination is similar to the ITRF2008, but where the EOPs are not included and involves local ties vectors instead of SINEX files, weighted by their diagonal terms only. In addition, the epochs of these tie vectors were assumed to be all the same, namely 2005.0. This combination shows slight changes of the estimated scale factors of SLR, GPS and DORIS with an increase of their uncertainties as well as the variance factor. The next combination test (Case-1) involves a selection of good ties that agree with space geodesy estimates to better than $1 \mathrm{~cm}$ (for the worst cases), but with a uniform weighting of $1 \mathrm{~mm}$ over all ties and components. Although the increase of the variance factor to 4.0 indicating that the weight given to

Table 3 Scale factors (at epoch 2005.0) from VLBI long-term solution to SLR, DORIS and GPS using different weighting and selection of local ties at co-location sites

\begin{tabular}{|c|c|c|c|c|c|}
\hline Case & SLR & DORIS & GPS & $\mathrm{VF}^{a}$ & Tie handling \\
\hline \multirow[t]{2}{*}{ ITRF2008 } & -1.05 & 0.18 & 0.67 & \multirow[t]{2}{*}{0.90} & \multirow[t]{2}{*}{ All tie SINEX files, weighted } \\
\hline & \pm 0.13 & \pm 0.20 & \pm 0.10 & & \\
\hline \multirow{2}{*}{$\begin{array}{l}\text { ITRF2008 } \\
\text { without EOPs }\end{array}$} & -1.11 & 0.04 & 0.41 & \multirow[t]{2}{*}{1.66} & \multirow[t]{2}{*}{ All tie vectors, weighted } \\
\hline & \pm 0.26 & \pm 0.31 & \pm 0.19 & & \\
\hline \multirow[t]{2}{*}{ Case-1 } & -1.20 & -0.31 & 0.49 & \multirow[t]{2}{*}{4.00} & \multirow[t]{2}{*}{ Selection of local ties, $\sigma=1 \mathrm{~mm}$} \\
\hline & \pm 0.16 & \pm 0.34 & \pm 0.14 & & \\
\hline \multirow[t]{2}{*}{ Case-2 } & -1.02 & -0.30 & 0.52 & \multirow[t]{2}{*}{31.70} & \multirow[t]{2}{*}{ Selection of local ties, $\sigma=0.1 \mathrm{~mm}$} \\
\hline & \pm 0.31 & \pm 0.84 & \pm 0.31 & & \\
\hline \multirow[t]{2}{*}{ Case-3 } & $0.0^{b}$ & 0.48 & 1.28 & \multirow[t]{2}{*}{4.28} & \multirow[t]{2}{*}{ Same as Case-1 } \\
\hline & & \pm 0.32 & \pm 0.08 & & \\
\hline
\end{tabular}

\footnotetext{
${ }^{a}$ Variance factor

${ }^{b}$ parameter eliminated from the normal equation; assumed to be equal to VLBI scale
} 
the local ties is too optimistic, this combination test increases the scale discrepancy between SLR and VLBI. The Case-2 test is the same as the previous one, but the local ties were given more weight by a factor of 10 . It yields a very large variance factor and still shows a scale discrepancy of $1.02 \mathrm{ppb}$ between SLR and VLBI solutions. The large variance factor obtained here is a clear indication that the heavy weight given to local ties increases considerably the normalized residuals, reflecting the discrepancies between space geodesy estimates and local ties that completely dominate this combination. The last test combination (Case-3) listed in Table 3 involves the same tie selection and weighting $(1 \mathrm{~mm})$ as Case- 1 , but where the SLR scale parameter was eliminated from the normal equation system (i.e. assuming zero scale difference with VLBI), this combination not only increases the variance factor, but it also insidiously transfers the SLR and VLBI scale discrepancy to GPS and DORIS. These test examples demonstrate that the adopted ITRF2008 final combination is the most statistically satisfactory combination. In addition, they show that the level of the scale agreement between VLBI and SLR solutions is not better than $1 \mathrm{ppb}$.

\subsection{Consistency between local ties and space geodesy estimates}

One of the most important by-products of the ITRF2008 combination is the assessment of the level of agreement between local ties and space geodesy estimates, through the availability of the post-fit residuals at co-location sites. In case of large discrepancies, discriminating between local ties and space geodesy estimates is a very delicate exercise, because the reasons for these discrepancies could be due to errors in local ties, in space geodesy estimates or in both. However, quantifying the level of agreement between the two ensembles is very critical for further investigation and hopefully for identifying the error sources. At co-location sites, not only station position residuals are computed, but also velocity residuals. Therefore, in order to take into account velocity disagreements between the technique solutions, it is more effective to compute the tie discrepancies at their measurement epochs. In order to identify the most performing co-location sites, we list in Table 4 the tie vectors where the discrepancies are less than $6 \mathrm{~mm}$ (corresponding to the level of scale consistency between VLBI and SLR solutions) in all three components: North, East and Up. As the GPS is playing the major role of connecting the three techniques together, the vectors listed in Table 4 are from GPS to other technique reference markers. With some exceptions, the geodetic instruments at the co-location sites listed in this table are still in operation in 2010. If we count the percentage of these sites listed in Table 4 over the total currently operating co-locations, we find approximately: 47, 43 and 34\% for GPS-VLBI, GPS-SLR and GPS-DORIS, respectively.
However, using this sub-set of local ties only, would result in a non-optimal combination. Indeed, a test combination that was performed involving these co-location sites only yielded an increase of the uncertainties of the estimated parameters by a factor of 3.4, compared to the results of the ITRF2008 combination. In particular, the obtained scale factor between VLBI and SLR is $0.83 \mathrm{ppb}$, but with an increase of its uncertainty: \pm 0.44 versus $\pm 0.13 \mathrm{ppb}$. In addition, we found the following percentages of co-location sites where tie discrepancies are larger than $10 \mathrm{~mm}: 29,28$ and 54\% for GPS-VLBI, GPS-SLR and GPS-DORIS, respectively. Rejecting these co-location sites from the ITRF2008 combination increases the uncertainties of the estimated parameters by a factor of 2 . Table 5 summarizes the tie discrepancy percentages following three categories: less than $6 \mathrm{~mm}$, between 6 and $10 \mathrm{~mm}$ and larger than $10 \mathrm{~mm}$.

The drawback of the GPS being the connecting technique is that any intrinsic GPS error would be transferred to the ITRF2008 estimated parameters. Therefore, properly weighting the local ties as a function of their agreement with space geodesy estimates is fundamental in order to ensure consistency between ITRF2008 results and individual technique solutions. Inspecting ITRF2008 local tie residuals, we found that some large discrepancies in the height component might be related to un-calibrated radomes covering the GPS antennas (Jim Ray and Ralf Schmid, personal communication). Examples of these cases include for GPSVLBI co-locations: Onsala (Sweden), Tidbinbilla (Australia), Santiago (Chile), Fort Davis (USA), and for GPS-SLR co-locations: Greenbelt (USA), Yarragadee (Australia). Another patent example of the radome effect is the case of Forteleza (Brazil) GPS-VLBI co-location site. Using the original local tie values obtained from the adjustment of the survey conducted in 1994 exhibited a tie discrepancy of $19 \mathrm{~mm}$ in the height component. Correction was then applied for the apparent height shift due to the neglected effect of the conical radome covering the GPS antenna as reported by Ray et al. (2007) which reduced the discrepancy to $2.3 \mathrm{~mm}$ (see Table 4, line "FORT"). However, there are sites with GPS radomes where the discrepancies are within the tie uncertainties, such as CRO1 (Saint-Croix, Virgin Islands, USA) and NYA1 (Ny-Alesund, Norway) as listed in Table 4.

There most probably are other technique-specific errors related to the mis-modeling of the instrumental measurement reference points, not only for GPS (Schmid et al. 2007), but also for the other techniques. Sarti et al. (2010) for instance evaluated the impact of signal path variations caused by VLBI antenna gravitational deformations for Medicina and Noto (Italy) telescopes. They found that applying an elevation-dependent model of the gravitational deformations in VLBI data analysis for these two antennas shift the reference point positions upward by 8.9 and $6.7 \mathrm{~mm}$, respectively. Applying this kind of elevation-dependent model to all VLBI 
Table 4 ITRF2008 tie discrepancies less than $6 \mathrm{~mm}$ at tie epochs in (E)ast, (N)orth and (U)p: Residuals = Space geodesy - terrestrial tie (in mm)

\begin{tabular}{|c|c|c|c|c|c|c|}
\hline CODE DOMES \# & CODE DOMES \# & East & North & Up & Epoch & Technique \\
\hline GRAS 10002M006 & $783510002 \mathrm{~S} 001$ & 1.3 & -3.6 & -5.6 & $99: 284$ & SLR \\
\hline GRAS 10002M006 & 7845 10002S002 & -1.1 & -1.2 & -0.6 & $99: 284$ & SLR \\
\hline TLSE $10003 \mathrm{M} 009$ & TLSA $10003 \mathrm{~S} 001$ & -1.2 & 0.7 & 2.3 & $4: 34$ & DORIS \\
\hline NYA1 10317M003 & SPIB 10317S004 & -1.2 & 5.7 & 2.2 & $3: 228$ & DORIS \\
\hline NYA1 10317M003 & SPJB 10317S005 & -1.9 & -0.8 & -0.9 & $3: 228$ & DORIS \\
\hline NYA1 10317M003 & $733110317 \mathrm{~S} 003$ & 2.9 & -2.7 & 1.2 & $3: 228$ & VLBI \\
\hline ONSA 10402M004 & 7213 10402S002 & 5.4 & -0.6 & -5.2 & $2: 193$ & VLBI \\
\hline GRAZ 11001M002 & 7839 11001S002 & 1.4 & -0.6 & -5.9 & $92: 319$ & SLR \\
\hline BOR1 12205M002 & 7811 12205S001 & 0.5 & 1.7 & -2.9 & $94: 10$ & SLR \\
\hline YSSK 12329M003 & SAKA 12329S001 & -0.4 & -2.3 & -2.9 & $4: 231$ & DORIS \\
\hline YSSK 12329M003 & SAKB 12329S002 & 2.3 & -5.0 & -2.3 & $4: 231$ & DORIS \\
\hline MATE 12734M008 & 7941 12734S008 & -3.7 & -4.7 & -1.6 & $4: 300$ & SLR \\
\hline HERS 13212M007 & $784013212 S 001$ & -1.2 & -3.1 & -2.4 & $8: 177$ & SLR \\
\hline ZIMM 14001M004 & $781014001 \mathrm{~S} 007$ & -1.9 & -2.2 & -5.2 & $96: 95$ & SLR \\
\hline WTZZ 14201M014 & $722414201 \mathrm{~S} 004$ & -1.4 & -4.1 & -0.3 & $2: 266$ & VLBI \\
\hline BJFS 21601M001 & 7249 21601S004 & 0.6 & 2.2 & 5.9 & $3: 171$ & SLR \\
\hline TSKB 21730S005 & 734521730 S007 & -2.9 & -0.8 & -3.0 & $8: 16$ & VLBI \\
\hline HRAO 30302M004 & 7232 30302S001 & -1.6 & 3.2 & 2.0 & $3: 214$ & VLBI \\
\hline HRAO 30302M004 & 7501 30302M003 & -2.2 & 2.6 & 3.5 & $3: 214$ & SLR \\
\hline HRAO 30302M004 & HBKB 30302S006 & 5.4 & -1.0 & -4.2 & $3: 214$ & DORIS \\
\hline NKLG 32809M002 & LIBB 32809S003 & 2.9 & 0.2 & 2.7 & $99: 36$ & DORIS \\
\hline STJO 40101M001 & 7625 40101M003 & 0.3 & 0.1 & 1.6 & $99: 269$ & VLBI \\
\hline YELL 40127M003 & 7285 40127M001 & -3.9 & -3.9 & -1.0 & $1: 285$ & VLBI \\
\hline PIE1 40456M001 & 7234 40456S001 & -3.1 & -2.8 & -0.3 & $92: 336$ & VLBI \\
\hline NLIB 40465M001 & 7612 40465S001 & -3.4 & -2.0 & -5.2 & $93: 64$ & VLBI \\
\hline MKEA 40477M001 & $761740477 \mathrm{~S} 001$ & -3.7 & -1.1 & 0.8 & $96: 221$ & VLBI \\
\hline MONP 40497M004 & MONB 40497S008 & 3.1 & -4.7 & -0.8 & $5: 335$ & DORIS \\
\hline MONP 40497M004 & 7110 40497M001 & 3.2 & -2.5 & 5.7 & $99: 280$ & SLR \\
\hline FORT 41602M001 & 729741602 S001 & -0.6 & -4.0 & 2.3 & $93: 264$ & VLBI \\
\hline GLPS 42005M002 & SCRB 42005S001 & -2.8 & -1.0 & -1.1 & $5: 92$ & DORIS \\
\hline CRO1 43201M001 & 7615 43201S001 & -1.5 & 2.2 & 1.6 & $94: 16$ & VLBI \\
\hline HOB2 50116M004 & $724250116 \mathrm{~S} 002$ & 4.7 & -3.0 & -2.0 & $2: 81$ & VLBI \\
\hline STR1 50119M002 & 7849 50119S001 & 4.1 & 0.1 & 4.0 & $1: 209$ & SLR \\
\hline CHAT 50207M001 & CHAB 50207S001 & 0.1 & 0.6 & -3.3 & $99: 56$ & DORIS \\
\hline SYOG 66006S002 & $734266006 \mathrm{~S} 004$ & 0.8 & 3.8 & 0.6 & $0: 1$ & VLBI \\
\hline KERG 91201M002 & KERB 91201S003 & -3.2 & -2.2 & 2.0 & $7: 101$ & DORIS \\
\hline DUM1 91501M001 & ADEB 91501S002 & -0.2 & -0.2 & 1.3 & $8: 39$ & DORIS \\
\hline DUM1 91501M001 & ADFB 91501S003 & -5.0 & -3.0 & 3.3 & $8: 39$ & DORIS \\
\hline THTI 92201M009 & PAPB 92201S007 & -1.3 & 1.7 & 4.4 & $7: 278$ & DORIS \\
\hline NOUM 92701M003 & NOUB 92701S002 & 0.5 & 5.8 & 2.2 & $5: 236$ & DORIS \\
\hline REUN 97401M003 & REUB 97401S002 & 0.4 & 2.5 & -1.0 & $3: 335$ & DORIS \\
\hline
\end{tabular}

The tie vectors are listed from GPS to other technique reference markers

antennas would probably increase its scale bias with respect to SLR. Appleby et al. (2009) reported that the introduction of a high-accuracy event timer at Herstmonceux (UK) SLR site in February 2007 has caused an apparent discontinuity in the laser range data, suggesting that the data prior to this date of equipment change is biased by $12 \mathrm{~mm}$. An appropriate correction was then applied by the ILRS for their ITRF2008 submission (Pavlis et al. 2010). As it can be seen in Table 4 
Table 5 Tie discrepancy percentage

\begin{tabular}{llll}
\hline Discrepancy $(\mathrm{mm})$ & GPS-VLBI & GPS-SLR & GPS-DORIS \\
\hline$<6$ & 47 & 43 & 34 \\
$6-10$ & 24 & 29 & 12 \\
$>10$ & 29 & 28 & 54 \\
\hline
\end{tabular}

(line HERS), the agreement between the local survey operated in June 2008 (IGN 2008) and space geodesy estimate is at the level of $3 \mathrm{~mm}$.

\subsection{ITRF2008 earth orientation parameters}

Similar to the ITRF2005 experience, ITRF2008 provides consistent series of polar motion and its daily rates, universal time (UT1-UTC) and Length of Day (LOD), with the latter being determined by VLBI uniquely. The reason for using LOD values from VLBI only is to avoid contaminating the VLBI estimates by biased determinations from satellite techniques (Ray 1996, 2009). In order to evaluate the EOP consistency between the four technique solutions, Fig. 7 displays the post fit polar motion residuals as result from the ITRF2008 combination, where it can be seen that GPS is dominating the three other techniques. It is worth noting that GPS polar motion helps tieing the three other technique solutions, via the two frame rotation parameters around the $X$ and $Y$-axes. The WRMS values computed over the post fit residuals between the combined and the individual polar motion time series are (for the couple $x$ and $y$ components): $(10,10)$, (142,120), (144,128), (239, 353) in micro-arc-seconds, for GPS, VLBI, SLR and DORIS, respectively.

\subsection{ITRF2008 performance in station positions and velocities}

In order to evaluate the ITRF2008 performance in station positions and velocities determination, we show the precision gain of these estimated parameters, compared to ITRF2005 results. Figure 8 illustrates for both frames the spherical
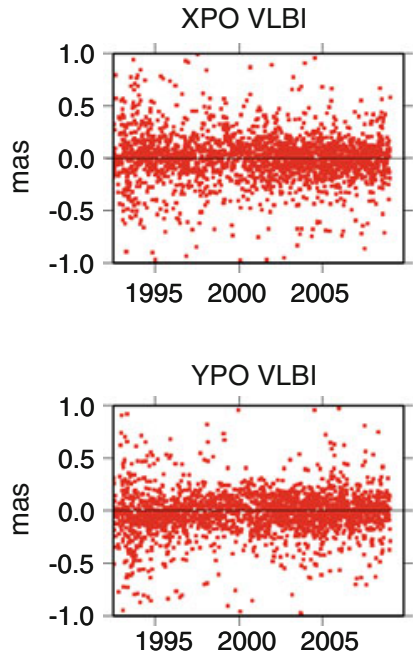
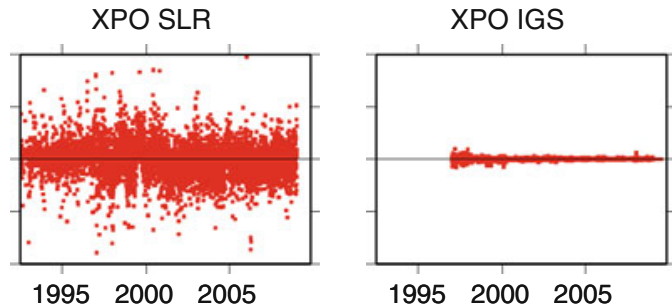

199520002005

YPO SLR
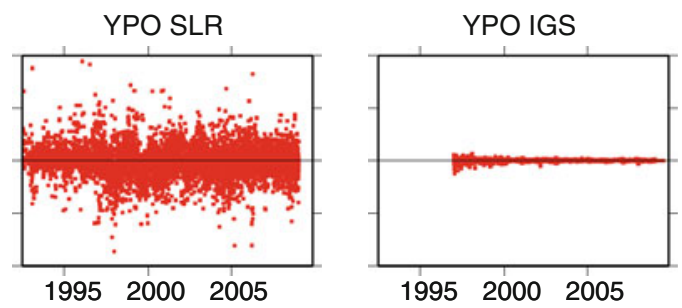
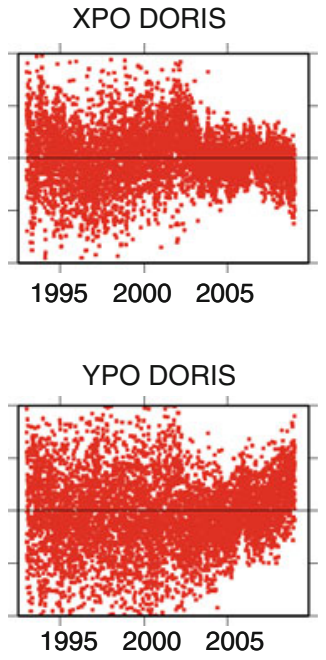

Fig. 7 ITRF2008 post fit residuals of polar motion in milli-arc-seconds
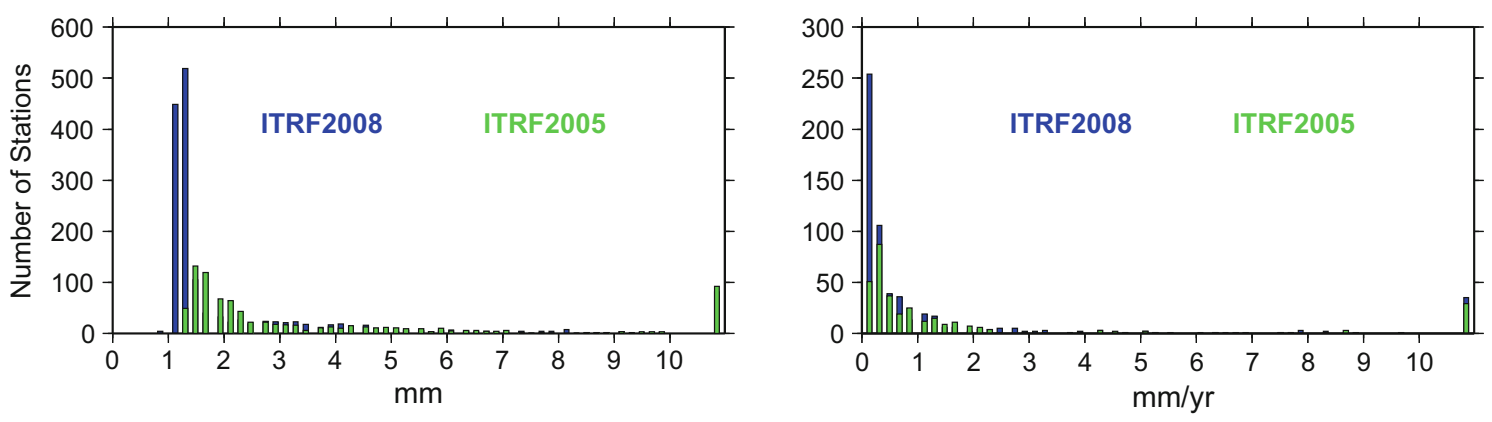

Fig. 8 Histogram of the ITRF2008 and ITRF2005 station position and velocity spherical errors 
Fig. 9 ITRF2008 horizontal velocities with formal error less than $0.2 \mathrm{~mm} / \mathrm{yr}$. Major plate boundaries are shown according to Bird (2003)
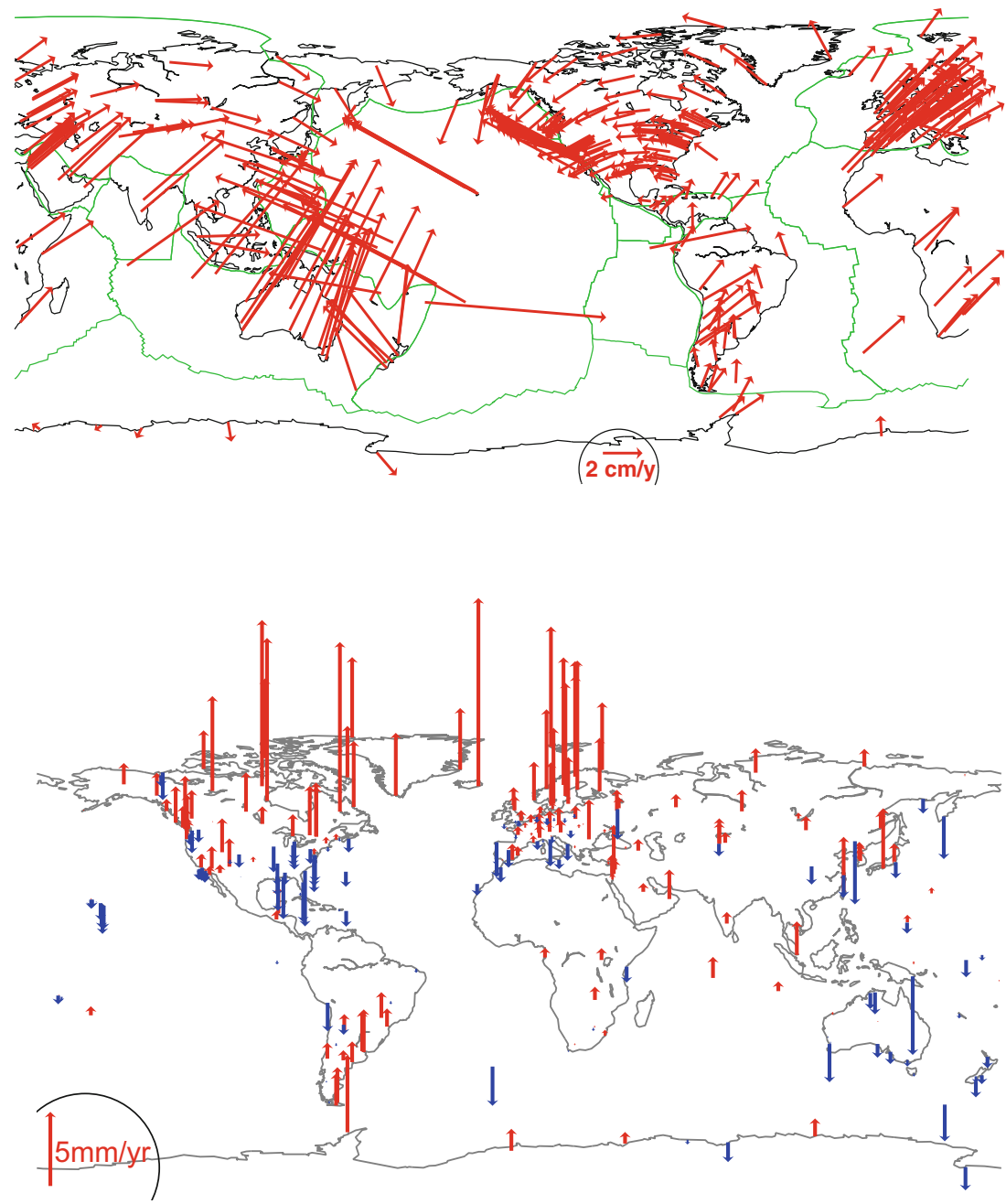

Fig. 10 ITRF2008 vertical velocities with formal error less than $0.2 \mathrm{~mm} / \mathrm{yr}$. Positive velocities are shown in red and negative in blue errors (computed following Altamimi et al. (2002b), Appendix A7) in station positions and velocities, showing the improvement achieved by ITRF2008. The station position spherical errors are computed at the epochs of minimum variances, following Altamimi et al. (2002b), Appendix A6, Eq. A22. They correspond, for each point position and velocity, to the square root of the square sum of the formal errors along the three components. Although these errors are very often believed to be optimistic (Williams et al. 2004), the proportion of ITRF2008 sites having greater precision as indicted by this figure is relatively high to demonstrate the well performance of ITRF2008 determination. The velocity error histogram shows a number of stations with errors greater than $10 \mathrm{~mm} / \mathrm{yr}$ which are due to short data spans for mostly old SLR and VLBI stations.

In addition, Figs. 9 and 10 show the ITRF2008 horizontal and vertical velocity fields, respectively, with formal error less than $0.2 \mathrm{~mm} / \mathrm{yr}$. At this high level of precision, ITRF2008 contains 406 sites in horizontal and 278 sites in vertical, versus 150 and 30 sites for ITRF2005.

\subsection{Transformation parameters between ITRF2008 and ITRF2005}

For many applications and in order to ensure the link between ITRF2008 and ITRF2005, it is essential to assess consistently the transformation parameters between the two frames. The same 179 stations (Fig. 3) that were used to ensure the alignment of the ITRF2008 orientation and its rate to the ITRF2005 were also used to estimate the transformation parameters between the two frames. The main criteria for selection of these 179 stations are (1) to have the best possible site distribution; (2) to involve as many as possible VLBI, SLR, GPS and DORIS stations and (3) to have the best agreement between the two frames in terms of postfit residuals of the 14-parameter transformation. Regarding this third criteria, the WRMS values of the 14-parameter similarity transformation fit are $2.4,2.9$ and $3.9 \mathrm{~mm}$ in position (at epoch 2005.0) and $0.4,0.4,0.7 \mathrm{~mm} / \mathrm{yr}$ in velocity, in east, north and vertical components, respectively. Table 6 lists the transformation parameters from ITRF2008 
Table 6 Transformation Parameters at epoch 2005.0 and their rates from ITRF2008 to ITRF2005, to be used with Eq. 4

\begin{tabular}{|c|c|c|c|c|c|c|c|}
\hline & $\begin{array}{l}T x(\mathrm{~mm}) \\
\dot{T} x(\mathrm{~mm} / \mathrm{yr})\end{array}$ & $\begin{array}{l}T y(\mathrm{~mm}) \\
\dot{T} y(\mathrm{~mm} / \mathrm{yr})\end{array}$ & $\begin{array}{l}T z(\mathrm{~mm}) \\
\dot{T} z(\mathrm{~mm} / \mathrm{yr})\end{array}$ & $\begin{array}{l}D(\mathrm{ppb}) \\
\dot{D}(\mathrm{ppb} / \mathrm{yr})\end{array}$ & $\begin{array}{l}R x \text { (mas) } \\
\dot{R} x(\mathrm{mas} / \mathrm{yr})\end{array}$ & $\begin{array}{l}R y \text { (mas) } \\
\dot{R} y \text { (mas/yr) }\end{array}$ & $\begin{array}{l}R z \text { (mas) } \\
\dot{R} z \text { (mas/yr) }\end{array}$ \\
\hline \multirow[t]{2}{*}{ \pm} & -0.5 & -0.9 & -4.7 & 0.94 & 0.00 & 0.00 & 0.00 \\
\hline & 0.2 & 0.2 & 0.2 & 0.03 & 0.08 & 0.08 & 0.08 \\
\hline \multirow[t]{2}{*}{ \pm} & 0.3 & 0.0 & 0.0 & 0.00 & 0.00 & 0.00 & 0.00 \\
\hline & 0.2 & 0.2 & 0.2 & 0.03 & 0.08 & 0.08 & 0.08 \\
\hline
\end{tabular}

to ITRF2005, to be used with the transformation formula given by Eq. (4).

$\left\{\begin{array}{l}\left(\begin{array}{l}x \\ y \\ z\end{array}\right)_{i 05}=\left(\begin{array}{l}x \\ y \\ z\end{array}\right)_{i 08}+T+D\left(\begin{array}{l}x \\ y \\ z\end{array}\right)_{i 08}+R\left(\begin{array}{l}x \\ y \\ z\end{array}\right)_{i 08} \\ \left(\begin{array}{l}\dot{x} \\ \dot{y} \\ \dot{z}\end{array}\right)_{i 05}=\left(\begin{array}{l}\dot{y} \\ \dot{y} \\ \dot{z}\end{array}\right)_{i 08}+\dot{T}+\dot{D}\left(\begin{array}{l}x \\ y \\ z\end{array}\right)_{i 08}+\dot{R}\left(\begin{array}{l}x \\ y \\ z\end{array}\right)_{i 08}\end{array}\right.$

where $i 05$ designates ITRF2005 and $i 08$ ITRF2008, $T$ is the translation vector, $T=\left(T_{x}, T_{y}, T_{z}\right)^{T}$, D is the scale factor and $\mathrm{R}$ is the matrix containing the rotation angles, given by

$R=\left(\begin{array}{ccc}0 & -R_{z} & R_{y} \\ R_{z} & 0 & -R_{x} \\ -R_{y} & R_{x} & 0\end{array}\right)$

The dotted parameters designate their time derivatives. The values of the 14 parameters are those listed in Table 6 . Note that the inverse transformation from ITRF2005 to ITRF2008 follows by interchanging (i08) with (i05) and changing the sign of the transformation parameters.

\section{Conclusion}

The ITRF2008 follows the series of constantly improved ITRF solutions thanks to the continuous improvements of the input data provided by the technique services and the combination strategy. The results presented in this paper demonstrate the high performance of the ITRF2008, compared with past solutions including the ITRF2005, not only in terms of precision of station positions and velocities, but also the improvement of its defining parameters, specifically the origin and the scale. While the accuracy of the ITRF2008 origin is difficult to assess, being determined by SLR only, we believe that its agreement with the ITRF2005 origin at the level of or better than $1 \mathrm{~cm}$ (at any epoch covering the time-span of the SLR observations) could be regarded as the level of the origin accuracy attainable today. An assessment of the scale discrepancy between the two independent techniques (VLBI and SLR) solutions, and hence the current scale accuracy, is believed to be at the level of $1.2 \mathrm{ppb}(8 \mathrm{~mm})$ over the common time-span of their observations covering about 26 years.

Thorough analysis and several test combinations have been undertaken during the ITRF2008 project to evaluate the impact of the local ties and their usage on the results and in particular on the frame defining parameters. We showed that using the local ties at their measurement epochs as observations and properly weighted with full variance covariance information provides the most statistically satisfactory combination. Although newly reprocessed solutions of the four techniques were used for the ITRF2008 generation, discrepancies between local surveys and space geodesy estimates still exist: $50 \%$ of the available SLR and VLBI tie vectors to GPS exhibit residuals larger than $6 \mathrm{~mm}$, and about $30 \%$ have residuals larger than $10 \mathrm{~mm}$. We identified that some large tie discrepancies might be due to the effect of un-calibrated radomes covering the GPS antennas in some IGS sites. However, including all available local ties properly weighted and if possible with full variance covariance information has been shown to lead to the best inter-technique combination.

As results from the ITRF2008 combination, we evaluate the uncertainty of the transfer of SLR origin and SLR and VLBI mean scale to GPS frame to be at the level of $0.6 \mathrm{~mm}$ at epoch 2005.0. This uncertainty would certainly be improved if we had a better geometry of co-location network with better agreement between space geodesy and local tie estimates. Therefore, the prerequisite for improving the ITRF is to start by improving the geodetic infrastructure.

Acknowledgments The ITRF activities are funded by the Institut Géographique National (IGN), France and partly by Centre National d'Etudes Spatiales (CNES). We are indebted to all Analysis and Combination Centers of the Technique Services of the four techniques who constantly provide data for ITRF solutions which would not exist without their valuable contributions. We are particularly grateful to all the institutions who provide the necessary budgets for the space geodesy observatories, which constitute the main ITRF foundation. Fruitful discussions and exchanges with DGFI group have been found very valuable for the benefit of the ITRF2008 project. We are grateful to R. Ferland, J-J. Valette, J. Griffith, S. McClusky and the DGFI group for their contribution to the GPS discontinuity list. Part of the work of Laurent Métivier is an IPGP contribution number 3125. We acknowledge useful comments and suggestions provided by two anonymous 
reviewers and Athanasios Dermanis which improved the content of this article.

Open Access This article is distributed under the terms of the Creative Commons Attribution Noncommercial License which permits any noncommercial use, distribution, and reproduction in any medium, provided the original author(s) and source are credited.

\section{References}

Altamimi Z, Boucher C, Sillard P (2002) New trends for the realization of the international terrestrial reference system. Adv Space Res 30(2):175-184

Altamimi Z, Sillard P, Boucher C (2002) ITRF2000: a new release of the international terrestrial reference frame for earth science applications. J Geophys Res 107(B10):2214. doi:10.1029/ 2001JB000561

Altamimi Z, Sillard P, Boucher C (2004) ITRF2000: from theory to implementation. In: Sansò F (ed) V Hotine-Marussi symposium on mathematical geodesy. International association of geodesy, 127. Springer, Berlin, pp 157-163

Altamimi Z, Collilieux X, Legrand J, Garayt B, Boucher C (2007) ITRF2005: a new release of the international terrestrial reference frame based on time series of station positions and earth orientation parameters 2007. J Geophys Res 112(B09401). doi:10.1029/ 2007JB004949

Altamimi Z, Collilieux X (2009) IGS contribution to the ITRF. J Geodesy 83(3-4):375-383. doi:10.1007/s00190-008-0294

Altamimi Z, Collilieux X (2010) Quality assessment of the IDS contribution to ITRF2008. In: Willis P (ed) DORIS: scientific applications in geodesy and geodynamics. Adv Space Res 45(12): 1500-1509. doi:10.1016/j.asr.2010.03.010

Altamimi Z, Dermanis A (2010) The choice of reference system in ITRF formulation. In: Proceedings of Hotine-Marussi symposium, Rome (in press)

Appleby GM, Wilkinson M, Luceri V, Gibbs P, Smith V (2009) Attempts to separate apparent observational range bias from true geodetic signals. In: Schilliak S (ed) Proceedings of the 16th international workshop on laser ranging. Posnan, Poland

Bähr H, Altamimi Z, Heck B (2007) Variance component estimation for combination of terrestrial reference frames. Universität Karlsruhe Schriftenreihe des Studiengangs Geodäsie und Geoinformatik 2007 6. ISBN:978-3-86644-206-1

Beckley BD, Lemoine FG, Luthcke SB, Ray RD, Zelensky NP (2007) A reassessment of global and regional mean sea level trends from TOPEX and Jason-1 altimetry based on revised frame and orbits. Geophys Res Lett 34(L14608). doi:10.1029/2007GL030002

Bianco G (2006) Agenzia Spaziale Italiana, provided local tie SINEX file for Matera site (personal communication)

Bird P (2003) An updated digital model of plate boundaries. Geochem Geophys Geosyst 4(3):1027. doi:10.1029/2001GC000252

Böckmann S, Artz T, Nothnagel A (2010) VLBI terrestrial reference frame contributions to ITRF2008. J Geod 84(3):201-219. doi:10. 1007/s00190-009-0357-7

Boehm J, Niell A, Tregoning P, Schuh H (2006) Global mapping function (GMF): a new empirical mapping function based on numerical weather model data. Geophys Res Lett 33(L07304). doi:10.1029/ 2005GL025546

Boehm J, Werl B, Schuh H (2006) Troposphere mapping functions for GPS and very long baseline interferometry from European Centre for Medium-Range Weather Forecasts operational analysis data. J Geophys Res Solid Earth 111:2406. doi:10.1029/2005JB003629
Boehm J, Heinkelmann R, Schuh H (2007) Short note: a global model of pressure and temperature for geodetic applications. J Geod 81: 679-683. doi:10.1007/s00190-007-0135-3

Collilieux X, Altamimi Z, Ray J, van Dam T, Wu X, (2009) Effect of the satellite laser ranging network distribution on geocenter motion estimation. J Geophys Res 114(B04402). doi:10.1029/ 2008JB005727

Collilieux X, Wöppelmann G (2010) Global sea-level rise and its relation to the terrestrial reference frame. J Geod. doi:10.1007/ s00190-010-0412-4

Collilieux X, Altamimi Z, Coulot D, van Dam T, Ray J (2010) Impact of loading effects on determination of the International Terrestrial Reference Frame. Adv Space Res 45:144-154. doi:10.1016/j.asr. 2009.08.024

Dermanis A (2000) Establishing global reference frames, nonlinear, temporal geophysical and stochastic aspects. In: Sideris M (ed) Gravity, geoid and geodynamics IAG symposium 123. pp 35-42

Dermanis A (2003) The rank deficiency in estimation theory and the definition of reference systems. In: Sansò F (ed) Hotine-Marussi symposium on mathematical geodesy, IAG Symposia 127, pp 145-156

Dong D, Dickey JO, Chao Y, Cheng M (1997) Geocenter variations caused by atmosphere, ocean and surface ground water. Geophys Res Lett 24:1867-1870. doi:10.1029/97GL01849

Dow J, Neilan RE, Rizos C (2009) The International GNSS Service in a changing landcape of Global Navigation Satellite Systems. J Geod 83(3-4):191-198

Farrell WE (1972) Deformation of the earth by surface loads. Rev Geophys 10(3):761-797

Ferland R, Piraszewski RM (2008) The IGS combined station coordinates, earth rotation parameters and apparent geocenter. J Geod 83:385-392. doi:10.1007/s00190-008-0295-9

Ferland R (2010) Description of IGS submission to ITRF2008. Available at: http://itrf.ensg.ign.fr/ITRF_solutions/2008/doc/ IGSsubmission4ITRF2008.txt

Geographical Survey Institute (GSI) (2010) VLBI Group, Space Geodesy Division, Tsukuba, Japan, provided local tie SINEX file for Tsukuba site (personal communication)

Gobinddass ML, Willis P, de Viron O, Sibthorpe A, Ries JC, Zelensky NP, Bar-Sever Y, Diament M, Ferland R (2009) Systematic biases in DORIS-derived geocenter time series related to solar pressure mis-modeling. J Geod 83(9):849-858. doi:10.1007/ s00190-009-0303-8

Greff-Lefftz M (2000) Secular variation of the geocenter. J Geophys Res 105(B11):25685-25692

Greff-Lefftz M, Métivier L, Besse J (2010) Dynamic mantle density heterogeneities and global geodetic observables. Geophys J Int 180:1080-1094. doi:10.1111/j.1365-246X.2009.04490.x

Haas G (2010) Onsala Space Observatory, provided local tie SINEX file for Onsala site (personal communication)

Institut Géographique National (IGN) (2008) Herstmonceux Co-location Survey, Reports and Results. Available at: http://itrf.ensg.ign. fr/doc_ITRF/Herstmonceux_Colocation_Survey_aug08.pdf

IUGG (2007) Resolution number 2 of Perugia IUGG General Assembly

Johnston G, Dawson J (2004) The 2003 Yarragadee (Moblas 5) Local Tie Survey, Geoscience Australia Record 2004/19. Available at: http://www.ga.gov.au/image_cache/GA5651.pdf

Kovalevsky J, Mueller II, Kolaczek B (eds) (1989) Reference frames in astronomy and geophysics. Kluwer Academic Publisher, Dordrecht $\mathrm{p} 474$

Lavallée D, van Dam T, Blewitt G, Clarke P(2006) Geocenter motions from GPS: a unified observation model. J Geophys Res 111(B10):B05405. doi:10.1029/2005JB003784

Mendes VB, Prates G, Pavlis EC, Pavlis D, Langley RB (2002) Improved mapping functions for atmospheric refraction correction in SLR. Geophys Res Lett 29(10). doi:10.1029/2001GL014394 
Mendes VB, Pavlis EC (2004) High-accuracy zenith delay prediction at optical wavelengths. Geophys Res Lett 31:14602. doi:10.1029/ 2004GL020308

Morel L, Willis P (2005) Terrestrial reference frame effects on global sea level rise determination from TOPEX/Poseidon altimetric data. Adv Space Res 36:358-368. doi:10.1016/j.asr.2005.05.113

Métivier L, Greff-Lefftz M, Altamimi Z (2010) On secular geocenter motion: the impact of climate changes, Earth and Planet. Sci Lett 296(3-4):360-366. doi:10.1016/j.epsl.2010.05.021

Nothnagel A (2009) Conventions on thermal expansion modelling of radio telescopes for geodetic and astrometric VLBI. J Geod 83: 787-792. doi:10.1007/s00190-008-0284-z

Pavlis E, Luceri C, Sciarretta C, Kelm R (2010) The ILRS contribution to ITRF2008. Available at: http://itrf.ensg.ign.fr/ITRF_solutions/ 2008/doc/ILRSSubmission4ITRF2008.pdf

Pearlman MR, Degnan JJ, Bosworth JM (2002) The international laser ranging service. Adv Space Res 30(2):135-143

Petit G, Luzum B, (eds.) (2010) IERS Conventions (2010), IERS Technical Note 36, Verlagdes Bundesamts für Kartographie und Geodäsie, Frankfurt am Main, Germany. http://tai.bipm.org/iers/ conv2010/

Ray JR (1996) Measurements of length of day using the Global Positioning System. J Geophys Res 101(B9):20141-20149

Ray JR, Crump D, Chin M (2007) New global positioning system reference station in Brazil. GPS Solut 11:1-10. doi:10.1007/ s10291-006-0032-x

Ray JR (2009) A Quasi-optimal, consistent approach for combination of UT1 and LOD. In: Drewes H (ed) Geodetic reference frames. International association of geodesy symposia, 2009, 134(Part 4):239243. Springer, Berlin. doi:10.1007/978-3-642-00860-3_37

Sarti P, Sillard P, Vittuari L (2004) Surveying co-located space-geodetic instruments for ITRF computation. J Geod 78(3): 210-222. doi:10.1007/s00190-004-0387-0

Sarti P, Abbondanza C, Vittuari L (2009) Gravity-dependent signal path variation in a large VLBI telescope modelled with a combination of surveying methods. J Geod 83(11):1115-1126. doi:10.1007/ s00190-009-0331-4

Sarti P, Abbondanza C, Petrov L, and Negusini M (2010) Height bias and scale effect induced by antenna gravity deformations in geodetic VLBI data analysis. J Geod. doi:10.1007/s00190-010-0410-6

Schmid R, Steigenberger P, Gendt G, Ge M, Rothacher M (2007) Generation of a consistent absolute phase-center correction model for GPS receiver and satellite antennas. J Geod 81:781-798. doi:10. 1007/s00190-007-0148-y
Schlüter W, Zernecke R, Becker S, Klügel Th, Thaller D (2004a) Local ties between the reference points at the fundamentalstation wettzell. In: Richter B, Dick WR, Schwegmann W (eds) IERS Technical Note 33. Verlag des Bundesamts für Kartographie und Geodäsie Frankfurt am Main, Germany

Schlüter W, Hase H, Zernecke R, Becker S, Klügel Th, Thaller D, (2004b) Local ties between the reference points at the transportable integrated geodetic observatory (TIGO) in Concepcion/Chile. In: Richter B, Dick WR, Schwegmann W (eds) IERS Technical Note 33. Verlag des Bundesamts für Kartographie und Geodäsie Frankfurt am Main, Germany

Schlüter W, Behrend D (2007) The international VLBI service for geodesy and astrometry (IVS). Current capabilities and future prospects. J Geod 81(6-8):379-387

Sillard P, Boucher C (2001) Review of algebraic constraints in terrestrial reference frame datum definition. J Geod 75:63-73

Tregoning P, Watson C (2009) Atmospheric effects and spurious signals in GPS analyses. J Geophys Res Solid Earth 114(B13):9403. doi:10.1029/2009JB006344

Valette JJ, Lemoine FG, Ferrage P, Yaya P, Altamimi Z, Willis P, Soudarin L (2010) IDS contribution to ITRF2008. In: Willis P (eds) DORIS: precise orbit determination and applications to the earth sciences. Adv Space Res. doi:10.1016/j.asr.2010.05.029

van Dam T, Altamimi Z, Collilieux X, Ray J (2010) Topographically induced height errors in predicted atmospheric loading effects. J Geophys Res 115(B07415) doi:10.1029/2009JB006810

Williams SDP, Bock Y, Fang P, Jamason P, Nikolaidis RM, Prawirodirdjo L, Miller M, Johnson DJ (2004) Error analysis of continuous GPS position time series. J Geophys Res 109(B03412). doi:10.1029/2003JB002741

Willis P, Fagard H, Ferrage P, Lemoine FG, Noll CE, Noomen R, Otten M, Ries JC, Rothacher M, Soudarin L, Tavernier G, Valette JJ (2010) The international DORIS service, toward maturity. In: Willis P (ed) DORIS: scientific applications in geodesy and geodynamics. Adv Space Res 45(12):1408-1420. doi:10.1016/j.asr. 2009.11.018

Zhu SY, Mueller II (1983) Effects of adopting new precession, nutation and equinox corrections on the terrestrial reference frame. Bull Geod 57:29-42 